\title{
Chromium burial in continental margin sediments
}

\author{
SYLVIE BRUGGMANN ${ }^{1,2}$, DAWID SZYMANOWSKI ${ }^{3}$, \\ SILKE SEVERMANN ${ }^{2}$, BLAIR SCHOENE ${ }^{3}$ AND JAMES \\ MCMANUS $^{4}$
}

${ }^{1}$ Vrije Universiteit Amsterdam

${ }^{2}$ Rutgers University

${ }^{3}$ Princeton University

${ }^{4}$ Bigelow Laboratory for Ocean Sciences

Presenting Author: s.bruggmann@vu.nl

Chromium $(\mathrm{Cr})$ is a redox sensitive trace metal and its variations in concentrations and isotope compositions $\left(\delta^{53} \mathrm{Cr}\right)$ in sedimentary rocks have been used to reconstruct past ocean chemical conditions. However, little is known about the transformations $\mathrm{Cr}$ is undergoing during early diagenesis and the mechanism by which it is incorporated into the marine sedimentary record. Here, we investigate $\mathrm{Cr}$ concentrations and isotope compositions in pore fluids and sediments to examine the effect of early diagenesis on $\mathrm{Cr}$ burial. Our study sites target the California and Mexico continental margins, which span a range of marine and sedimentary chemical conditions. In particular, these sites exhibit a range in bottom water oxygen concentrations from $<0.1$ to $130 \mu \mathrm{M}$, and in organic carbon burial rates from 0.08 to $8.4 \mathrm{mmol} \mathrm{m}^{-2} \mathrm{~d}^{-1}$. Additionally, two stations show high solid Mn concentrations (up to $2.3 \%$ ) near the sediment surface.

Under sulfidic, organic-rich sedimentary conditions, dissolved $\mathrm{Cr}$ in pore fluids increases with depth $(>50 \mathrm{nM})$, which we interpret as $\mathrm{Cr}$ release from decomposing organic matter. In contrast, under oxic, organic-poor conditions, with low to high Mn concentrations, dissolved Cr typically remains below $10 \mathrm{nM}$. Hence, reductive dissolution of $\mathrm{Mn}$ oxides does not appear to release dissolved $\mathrm{Cr}$. Preliminary d53Cr values in sediment extracts $(1 \mathrm{M} \mathrm{HCl})$ are highest (nearly $1 \%$ ) in reducing organicrich sediments, whereas the $\delta^{53} \mathrm{Cr}$ values at our other study sites are lower, with an average value of approximately $0.2 \%$. Collectively, our data suggest that organic matter burial and potentially the presence of $\mathrm{Mn}$ oxides play key roles in setting the $\mathrm{Cr}$ isotope sedimentary record. 